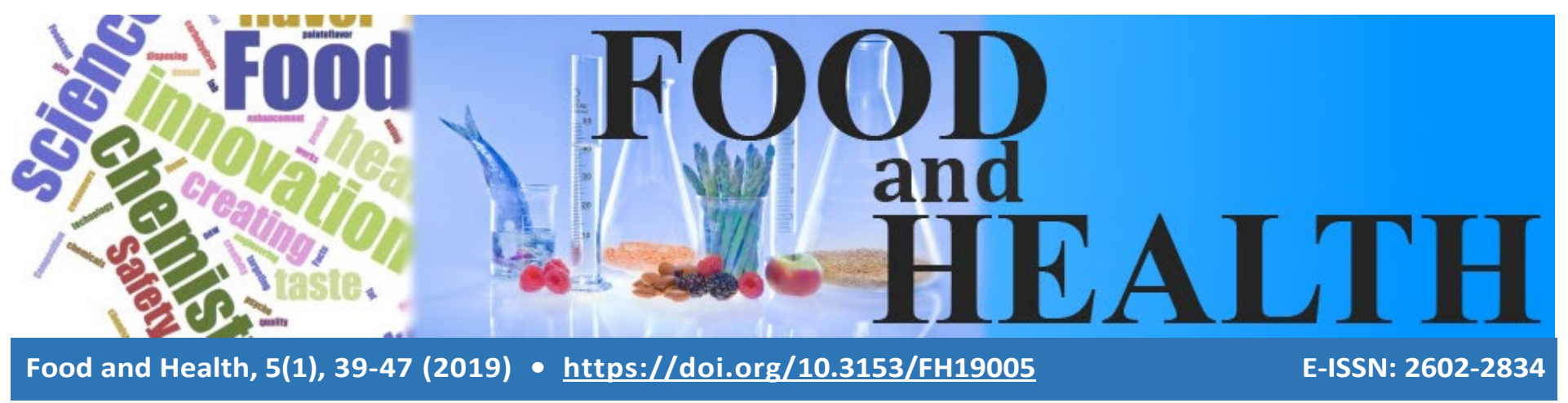

Research Article

\title{
EVALUATION OF ANTIOXIDANT AND CHOLINESTERASE INHIBITORY ACTIVITIES OF SOME MEDICINAL PLANTS
}

\author{
Ezgican Ulaç ${ }^{\mathbb{D}}$, Pelin Köseoğlu Yılmaz ${ }^{\mathbb{D}}$, Ufuk Kolak ${ }^{(\mathbb{D}}$
}

Cite this article as:

Ulaç, E., Köseoğlu Yılmaz, P., Kolak, U. (2019). Evaluation of Antioxidant and Cholinesterase Inhibitory Activities of Some Medicinal Plants. Food and Health, 5(1), 39-47. https://doi.org/10.3153/FH19005

Istanbul University, Faculty of Pharmacy, Department of Analytical Chemistry, Beyazit Istanbul, Turkey

Submitted: 19.01 .2018

Accepted: 24.05 .2018

Published online: 08.10.2018

Correspondence:

Ufuk KOLAK

E-mail: kolak@istanbul.edu.tr

๑ Copyright 2019 by ScientificWebJournals

Available online at

http://jifhs.scientificwebjournals.com

\begin{abstract}
The aim of this study was to determine total phenolic and total flavonoid contents, antioxidant and anticholinesterase activities of the hexane, acetone and ethanol extracts prepared from mantle, rosemary, thistle, mallow and nettle commonly consumed for medicinal and nutraceutical purposes in Turkey and all around the world. DPPH free radical, ABTS cation radical and superoxide anion radical scavenging assays, and Ellman method were used to establish the antioxidant and anticholinesterase potential of the extracts, respectively. Total phenolic and total flavonoid contents of the mantle ethanol extract were found to be the richest extract among the others. Mantle ethanol and thistle hexane extracts in DPPH free radical scavenging method ( $88.03 \%$ and $88.07 \%$, respectively), and acetone and ethanol extracts of mantle and rosemary in ABTS cation radical scavenging assay showed the highest inhibition $(88.60 \%$ and $89.73 \%$, respectively) at $100 \mu \mathrm{g} / \mathrm{mL}$ concentration. None of the extracts exhibited superoxide anion radical scavenging activity. Nettle ethanol extract indicated higher butyrylcholinesterase inhibitory activity $(92.68 \%)$ than galanthamine, mallow acetone extract as galanthamine, mantle hexane, mallow hexane and ethanol, and nettle acetone extracts almost as galanthamine. To our knowledge, ABTS cation radical and superoxide anion radical scavenging activities, and anticholinesterase potential of the extracts prepared from mantle leaves and flowers, anticholinesterase effect of thistle seeds extracts, ABTS cation radical scavenging activity and butyrylcholinesterase inhibitory activity of the extracts prepared from mallow leaves and flowers were investigated for the first time in this study.
\end{abstract}

Keywords: Medicinal Plant, Total Phenolic, Total Flavonoid, Antioxidant, Anticholinesterase 


\section{Introduction}

Reactive oxygen species (ROS) are intermediates of the respiration process, which in excess can damage proteins, lipids, and DNA. The harmful effects of ROS cause oxidative stress. Oxidative stress is generated when the reduction of ROS is not balanced by the antioxidative defense mechanisms such as radical scavenging enzymes and cellular antioxidants. Oxidative stress has been considered as the cause of aging and some serious health problems like diabetes mellitus, cataracts, cancer, neurodegenerative, and cardiovascular diseases. Therefore, it has gained attention to find ways accomplishing the prevention of excess ROS generation for a healthy biological system (Dudonné et al., 2009; Boğa et al., 2011). A diet including fruits and vegetables has been suggested for protection against oxidative stress sourced diseases. Dietary antioxidants have positive effects on cellular defences and oxidative stress to cellular component by scavenging free radicals and possibly reducing oxidized fatty acids or mutagens (Reische et al., 2002; Wong et al., 2006).

Antioxidants are also utilized in food industry to extend the shelf life and prevent degradation. Generally synthetic antioxidants such as butylated hydroxyanisole (BHA) and butylated hyrdroxytoluene (BHT) are used for this purpose. On the other hand, it has been revealed that synthetic antioxidants and their by-products might cause some health issues (Boğa et al., 2016). Therefore, searching for antioxidants from natural sources has become an important study field, including identification of new active compounds. In addition, these naturally occurring antioxidants can be formulated as nutraceuticals (Dudonné et al., 2009).

Antioxidants in plants, such as vitamins (e.g., ascorbic acid, $\alpha$-tocopherol), minerals (e.g., selenium, zinc) and organic compounds (e.g., phenols, terpenes, organosulfurs), not only neutralize ROS by giving up electrons, but also have roles in other biological mechanisms. Galanthamine, which is isolated from daffodils, is an acetylcholinesterase (AChE) inhibitor and currently used to control Alzheimer's disease (AD) (Hartman, 2009). AD is a neurodegenerative disease which especially affects the elderly population. Fifty percent to $60 \%$ of dementia cases in people over 65 years is caused by $\mathrm{AD}$. Although the main reason of $\mathrm{AD}$ is not still elucidated completely, it is associated with a loss of the presynaptic markers of the cholinergic system in memory and learning areas of the brain. AD is characterized by the presence of amyloid deposits and neurofibrillary tangles in the brain (Piazzi et al., 2008). Generally two approaches are followed in the treatment of AD to enhance the cholinergic sys- tem as stimulation of the cholinergic receptors and inhibition of acetylcholine hydrolysis by AChE (Howes et al., 2003).

Medicinal plants have been used for treatment of various diseases since ancient times. Biologically active compounds isolated from these plants are still important sources for modern drug formulations and nutraceuticals (Samuelsson, 1999; Nasri et al., 2014). Natural products are known to have fewer or no side effects compared to synthetics which makes them more preferable (Ertaş et al., 2014). Mantle (Aphanes arvensis L.), rosemary (Rosmarinus officinalis L.), thistle (Silybum marianum L.), mallow (Malva sylvestris $\mathrm{L}$.), and nettle (Urtica dioica $\mathrm{L}$.) are medicinal plants used in Turkey and all around the world. All of them have been used for digestive system diseases as traditional medicines (Baytop, 1984). In this study, antioxidant and anticholinesterase activities of the hexane, acetone and ethanol extracts of these plants were determined with their total phenolic and flavonoid contents. DPPH free radical, ABTS cation radical and superoxide anion radical scavenging assays were applied for the evaluation of the antioxidant effects, whereas the anticholinesterase activities were determined by the Ellman method.

\section{Materials and Methods}

\section{Chemicals}

Quercetin, pyrocatechol, 1,1-diphenyl-2-picrylhydrazyl (DPPH), BHA, potassium iodide (KI), 5,5-dithiobis(2nitro benzoic acid) (DTNB), nicotineamide adenine dinucleotide (NADH), phenazine methosulfate (PMS), nitroblue tetrazolium (NBT), $\alpha$-tocopherol ( $\alpha$-Toc), gallic acid, potassium peroxydisulfate $\left(\mathrm{K}_{2} \mathrm{~S}_{2} \mathrm{O}_{8}\right)$, 2,2-azinobis (3-ethylbenzothiazoline-6-sulfonic acid) (ABTS) were purchased from Sigma (USA). Hexane, acetone, aluminum nitrate $\left(\mathrm{Al}\left(\mathrm{NO}_{3}\right)_{3} .9 \mathrm{H}_{2} \mathrm{O}\right)$, potassium acetate $\left(\mathrm{CH}_{3} \mathrm{COOK}\right)$ were from Merck (Germany). Sodium hydrogen phosphate $\left(\mathrm{Na}_{2} \mathrm{HPO}_{4} \cdot 2 \mathrm{H}_{2} \mathrm{O}\right)$, sodium dihydrogen phosphate $\left(\mathrm{NaH}_{2} \mathrm{PO}_{4} \cdot 2 \mathrm{H}_{2} \mathrm{O}\right)$, galanthamine hydrobromide, (+)-catechin (Cat), AChE (498,3498 U) and butyrylcholinesterase (BChE) $(11,4 \mathrm{U})$ were purchased from Sigma-Aldrich (USA). Acetylcholine iodide (AcI) and Folin-Ciocalteu reagent (FCR) were from Applichem (Germany). Butyrylcholine iodide (BuI) was from Fluka (Switzerland). Sodium carbonate $\left(\mathrm{Na}_{2} \mathrm{CO}_{3}\right)$ was from Riedel-de-Haën (Germany).

\section{Instrumentation}

Spectrophotometric analyses were performed by a Power Wave XS microplate spectrophotometer (BioTek, USA). 


\section{Plant Material}

Mantle (leaves and flowers), rosemary (leaves), thistle (seeds), mallow (leaves and flowers) and nettle (leaves) samples were purchased from local market in Istanbul in February, 2014.

\section{Plant Extracts}

Plant materials were pulverized. Five grams of the grounded plant material was macerated triplicate with hexane, acetone and ethanol for one hour. The solvent was evaporated under reduced pressure. Classification of the extracts, and the extraction yields were given in Table 1.

\section{Total Phenolic and Total Flavonoid Contents}

The calibration curve was prepared with standard pyrocatechol solutions in the concentration range of $0.5-4.0 \mu \mathrm{g} / \mathrm{mL}$. The sample solutions were prepared at a concentration of $1000 \mathrm{mg} / \mathrm{L}$ with ethanol. A volume of $4.0 \mu \mathrm{L}$ of the sample solution was mixed with $180 \mu \mathrm{L}$ of distilled water, $4.0 \mu \mathrm{L}$ FCR and $12.0 \mu \mathrm{L}$ of $2 \% \mathrm{Na}_{2} \mathrm{CO}_{3}$ solution. The mixture was kept at ambient temperature for 2 hours. The absorbance of the sample was measured at $760 \mathrm{~nm}$ and the total phenolic content results were expressed as pyrocatechol equivalents (PE) (Slinkard and Singleton, 1977).

The calibration curve of quercetin was prepared in the concentration range of $5-40 \mu \mathrm{g} / \mathrm{mL}$ for the determination of total flavonoid content. A volume of $20 \mu \mathrm{L}$ of sample solution was mixed with $172 \mu \mathrm{L}$ of $80 \%$ ethanol and $4 \mu \mathrm{L}$ of 1.0 $\mathrm{mol} / \mathrm{L} \mathrm{CH}_{3} \mathrm{COOK}$ solution. After 1 minute, $4 \mu \mathrm{L}$ of $10 \%$ $\mathrm{Al}\left(\mathrm{NO}_{3}\right)_{3}$ solution was added to the mixture. The absorbance was measured at $415 \mathrm{~nm}$ after 40 minutes. The total flavonoid contents were expressed as quercetin equivalents (QE) (Park et al. 1997).

Total phenolic and total flavonoid contents were calculated according to the following equations, respectively:

Absorbance $=0.0341(\mu \mathrm{g}$ pyrocatechol $)+0.0420$

$\mathrm{R}^{2}=0.9945$

Absorbance $=0.0269(\mu$ g quercetin $)+0.0211$

$\mathrm{R}^{2}=0.9950$

\section{DPPH Free Radical Scavenging Assay}

Four milligrams of DPPH was dissolved in $100 \mathrm{~mL}$ of ethanol and the solution was mixed for half an hour in the dark to prepare the DPPH radical solution. Different volumes of sample solution $(2,5,10,20 \mu \mathrm{L})$ taken from stock solution $(1000 \mathrm{mg} / \mathrm{L})$ were completed to $40 \mu \mathrm{L}$ with distilled water and mixed with $160 \mu \mathrm{L}$ of DPPH radical solution. The absorbance was measured at $517 \mathrm{~nm}$ after 30 min of incubation at ambient temperature. BHA and $\alpha$-Toc were used as the standards. The results were expressed as inhibition \% (Blois, 1958).

Table 1. Classification of the extracts and the extraction yields

\begin{tabular}{llll}
\hline Plant material & Extract & Code & Extraction yield (\%) \\
\hline Mantle & Hexane extract & MNH & 0.63 \\
& Aceone extract & MNA & 2.31 \\
\multirow{3}{*}{ Rosemary } & Ethanol extract & MNE & 4.10 \\
& Hexane extract & RH & 18.00 \\
\multirow{4}{*}{ Thistle } & Aceone extract & RA & 14.99 \\
& Ethanol extract & RE & 20.97 \\
& Hexane extract & TH & 12.90 \\
Mallow & Aceone extract & TA & 18.18 \\
& Ethanol extract & TE & 18.03 \\
\multirow{4}{*}{ Nettle } & Hexane extract & MH & 0.70 \\
& Aceone extract & MA & 2.20 \\
& Ethanol extract & ME & 2.37 \\
& Hexane extract & NH & 0.65 \\
& Aceone extract & NA & 0.91 \\
& Ethanol extract & NE & 2.45 \\
\hline
\end{tabular}




\section{ABTS Cation Radical Scavenging Assay}

The ABTS cation radical solution was prepared by dissolving $19.2 \mathrm{mg}$ of ABTS and $3.3 \mathrm{mg}$ of $\mathrm{K}_{2} \mathrm{~S}_{2} \mathrm{O}_{3}$ in $5 \mathrm{~mL}$ of distilled water. The solution was kept in dark for 16 hours at ambient temperature and then diluted to fix its absorbance to approximately 0.70 at $734 \mathrm{~nm}$. Different volumes of sample solution $(2,5,10,20 \mu \mathrm{L})$ taken from stock solution $(1000 \mathrm{mg} / \mathrm{L})$ were completed to $40 \mu \mathrm{L}$ with distilled water and mixed with $160 \mu \mathrm{L}$ of ABTS cation radical solution. After 6 minutes of incubation at ambient temperature, absorbance was measured at $734 \mathrm{~nm}$. BHA and (+)-catechin (Cat) were the standards. The results were given in terms of inhibition \% (Pellegrini et al., 1999).

\section{Superoxide Anion Radical Scavenging Assay}

Stock solutions of the samples were prepared at $2500 \mathrm{mg} / \mathrm{L}$ with ethanol. Volumes of stock solution as $0.88,2.2,4.4$ and $8.8 \mu \mathrm{L}$ were completed to $10 \mu \mathrm{L}$ with distilled water. Then, $100 \mu \mathrm{L}$ of NBT solution $(156 \mu \mathrm{M}), 100 \mu \mathrm{L}$ of NADH solution $(468 \mu \mathrm{M})$ and $10 \mu \mathrm{L}$ of PMS solution $(60 \mu \mathrm{M})$ were added. Sample was kept at $25{ }^{\circ} \mathrm{C}$ for 5 minutes and absorbance was measured at $560 \mathrm{~nm}$. Gallic acid was used as the standard. The results were calculated as inhibition \% (Nishikimi et al., 1972).

Anticholinesterase Assay
The anticholinesterase activities of the samples were determined by the Ellman method as their $\mathrm{AChE}$ and $\mathrm{BChE}$ inhibition potentials. The sample solutions $(4000 \mathrm{mg} / \mathrm{L})$ were prepared in ethanol. Volumes of $130 \mathrm{~mL}$ of $100 \mathrm{mmol} / \mathrm{L}$ phosphate buffer ( $\mathrm{pH} 8.0), 10 \mu \mathrm{L}$ of sample solution and 20 $\mu \mathrm{L}$ of $\mathrm{AChE}$ (or BChE) solution were mixed and incubated for $15 \mathrm{~min}$ at $25^{\circ} \mathrm{C}$. Aliquot of $20 \mu \mathrm{L}$ of DTNB solution (prepared by $2.0 \mathrm{~mL}$ of $\mathrm{pH} 7.0$ and $4.0 \mathrm{~mL}$ of $\mathrm{pH} 8.0$ phosphate buffer, $1.0 \mathrm{~mL}$ of $16 \mathrm{mg} / \mathrm{mL}$ DTNB solution and $7.5 \mathrm{mg} / \mathrm{mL}$ $\mathrm{NaHCO}_{3}$ in $\mathrm{pH} 7.0$ phosphate buffer) was added. The reaction was initiated by the addition of $20 \mu \mathrm{L} \mathrm{AcI} \mathrm{(or} \mathrm{BuI).} \mathrm{The}$ hydrolysis of these substrates was monitored at $412 \mathrm{~nm}$ (Ellman et al., 1961). Galanthamine was used as the standard. The results were given in inhibition $\%$.

\section{Statistical Analysis}

All of the analyses were performed in triplicate measurements and given as the mean \pm standard deviation (SD). Data were analyzed using Microsoft Excel 2016.

\section{Results and Discussion}

\section{Total Phenolic and Total Flavonoid Contents}

Total phenolic and total flavonoid contents of the hexane, acetone and ethanol extracts of five medicinal plants were calculated as pyrocatechol and quercetin equivalents, respectively (Table 2). It was determined that MNE had the highest phenolic and flavonoid contents. In addition, MNA, MA and NE were found to be particularly rich in flavonoids.

Table 2. Total phenolic and total flavonoid contents of the plant extracts ${ }^{\mathrm{a}}$

\begin{tabular}{lll}
\hline Extracts & $\begin{array}{l}\text { Total phenolic content } \\
(\boldsymbol{\mu g} \text { pyrocatechol/mg extract) }\end{array}$ & $\begin{array}{l}\text { Total flavonoid content } \\
(\boldsymbol{\mu g} \text { quercetin/mg extract) }\end{array}$ \\
\hline MNH & $5.38 \pm 0.05$ & $18.67 \pm 1.69$ \\
MNA & $46.92 \pm 3.88$ & $81.37 \pm 2.57$ \\
MNE & $164.22 \pm 1.47$ & $114.36 \pm 2.69$ \\
RH & $66.47 \pm 1.69$ & $31.437 \pm 2.42$ \\
RA & $13.68 \pm 2.24$ & $15.20 \pm 0.74$ \\
RE & $22.48 \pm 0.85$ & $21.40 \pm 0.77$ \\
TH & $7.82 \pm 1.05$ & $47.05 \pm 1.27$ \\
TA & $7.82 \pm 0.85$ & $40.11 \pm 1.83$ \\
TE & $11.73 \pm 0.00$ & $33.29 \pm 1.41$ \\
MH & $20.53 \pm 1.47$ & $25.36 \pm 0.56$ \\
MA & $17.59 \pm 2.54$ & $87.82 \pm 2.84$ \\
ME & $11.24 \pm 1.39$ & $29.70 \pm 0.37$ \\
NH & $12.21 \pm 2.24$ & $27.84 \pm 1.28$ \\
NA & $17.59 \pm 1.47$ & $54.36 \pm 1.54$ \\
NE & $13.19 \pm 1.72$ & $83.97 \pm 3.17$ \\
\hline
\end{tabular}

\footnotetext{
${ }^{a}$ Mean of triplicate measurements \pm standard deviation

${ }^{\mathrm{b}}$ Phenolic content in terms of pyrocatechol equivalents per gram of dry extract $\left(\mathrm{y}=0.0341 \mathrm{x}+0.0420 \mathrm{R}^{2}=0.9945\right)$

${ }^{c}$ Flavonoid content in terms of quercetin equivalents per gram of dry extract $\left(y=0.0269 x+0.0211 R^{2}=0.9950\right)$
} 


\section{Antioxidant Activity Assays}

Antioxidants react with radicals by mechanisms as hydrogen atom transfer (HAT), single electron transfer (SET), or both, mainly. In HAT mechanisms, the free radical removes one hydrogen atom of antioxidant, and the antioxidant itself becomes a radical. In SET mechanisms, the antioxidant provides an electron to the free radical and then itself becomes a radical cation (Liang and Kitts, 2014). ABTS cation radical scavenging is a mixed-mode assay since ABTS can be neutralized by both SET and HAT. DPPH free radical scavenging assay depends on SET mechanism (Craft et al., 2012).

In the present study antioxidant capacities of the hexane, acetone and ethanol extracts of the selected medicinal plants were investigated. The radical scavenging potentials were determined by DPPH free radical, ABTS cation radical and superoxide anion radical scavenging assays. To the best of our knowledge, ABTS cation radical and superoxide anion radical scavenging activity and anticholinesterase potential of the mantle leaves and flowers extracts, anticholinesterase activity of thistle seeds extracts, ABTS cation radical scavenging activity and BChE inhibitory activity of the extracts prepared from mallow leaves and flowers were investigated for the first time.

DPPH free radical scavenging assay is based on a color change, (the purple color of unstable DPPH to the yellow color of stable DPPH-H) by capturing hydrogen. The scavenging effects of the extracts were investigated at four different concentrations $(10,25,50,100 \mu \mathrm{g} / \mathrm{mL}$ ) (Figure 1). The results were compared with BHA and $\alpha$-Toc which were used as the standard antioxidants. At 50 and 100 $\mu \mathrm{g} / \mathrm{mL}$ concentrations, MNE, TH and TA had higher DPPH free radical scavenging activity ( $>80 \%$ inhibition) than the other extracts, which were similar to inhibition \% of BHA and $\alpha$-Toc. MH and NA showed almost the same effect with the standards at $100 \mu \mathrm{g} / \mathrm{mL}$.

ABTS cation radical assay is based on the reduction of ABTS cation radical by antioxidants of the extracts. The ABTS cation radical scavenging activity of the extracts were determined at 10, 25, 50,100 $\mathrm{g} / \mathrm{mL}$ (Figure 2). MNE exhibited higher scavenging effect than the other extracts at $10,25,50 \mu \mathrm{g} / \mathrm{mL}$ concentrations. MNA, MNE, RA and RE had approximately the same ABTS cation radical scavenging potential $(\sim 90 \%$ inhibition) with BHA and Cat which were the standard compounds at $100 \mu \mathrm{g} / \mathrm{mL}$ concentration. While RH showed $85 \%$ inhibition at the same concentration, other extracts indicated below $80 \%$ inhibition.
The superoxide anion radical scavenging activity of the extracts were investigated at four different concentrations (10, $25,50,100 \mu \mathrm{g} / \mathrm{mL}$ ). Gallic acid was used as the standard compound. None of the tested extracts showed superoxide anion radical scavenging activity. Gülçin et al. also revealed that water extract of nettle had no superoxide anion radical scavenging effect (Gülçin et al., 2004).

MNE was determined as a potent antioxidant source, since it showed high radical scavenging effect similar to the standard antioxidant compounds in both DPPH and ABTS assays with highest total phenolic and total flavonoid contents. Hamad et al. investigated the DPPH free radical scavenging activity of methanol extract of mantle leaves and obtained similar potentials with those of trolox and vitamin $\mathrm{C}$ (Hamad et al., 2010). MNA, RA and RE had particular ABTS cation radical scavenging activity. In another study, ethanol extract of rosemary tea indicated relatively high antioxidant potential in both DPPH and ABTS assays (Oh et al., 2012). Benso et al. investigated the DPPH free and ABTS cation radical scavenging effects of mallow leaves extracts (aqueous, ethanol, ethyl acetate, chloroform and hexane) in terms of $\mathrm{IC}_{50}$ and trolox equivalent, respectively (Benso et al., 2016). Distinctly, antioxidant effect of ethanol, acetone and hexane extracts of mallow leaves and flowers together were determined as inhibition $\%$ in the present study.

\section{Anticholinesterase Assay}

The anticholinesterase activity of the hexane, acetone and ethanol extracts were determined by Ellman method at 200 $\mu \mathrm{g} / \mathrm{mL}$ concentration. This method depends on the absorbance measurement of the yellow color occuring as a result of the thio anion produced by the enzymatic hydrolysis of the substrate (AcI or BuI) reacting with DTNB (Ellman et al., 1961). The results were compared with the standard drug, galanthamine. None of the extracts had high AChE inhibition effect. Orhan et al. also reported that petroleum ether, chloroform, ethyl acetate and methanol extracts of rosemary had no AChE inhibition effect (Orhan et al., 2008). In addition, researchers found out that methanol extract of mallow flowers and ethanol extract of the aerial parts of mallow were inactive in $\mathrm{AChE}$ inhibition assay (Gholamhoseinian et al., 2009; Ferreria et al., 2006). On the other hand, mallow was found to be an important BChE inhibitor since all of the mallow extracts had similar activities with galanthamine. Moreover, NE showed higher $\mathrm{BChE}$ inhibition than galanthamine (Table 3). 


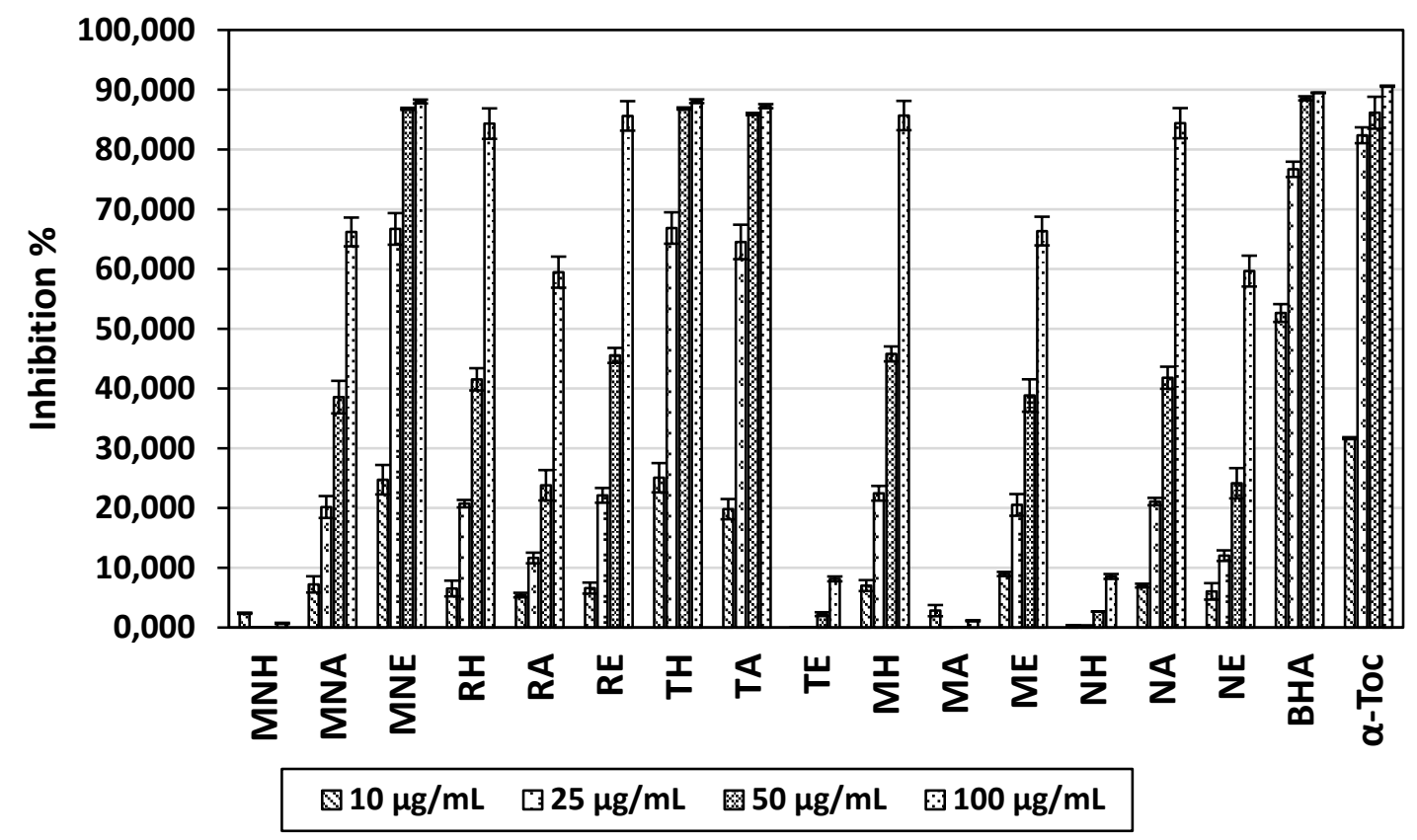

${ }^{a}$ Mean of triplicate measurements \pm standard deviation

Figure 1. DPPH free radical scavenging activity of the plant extracts, BHA and $\alpha$-Toc ${ }^{\mathrm{a}}$

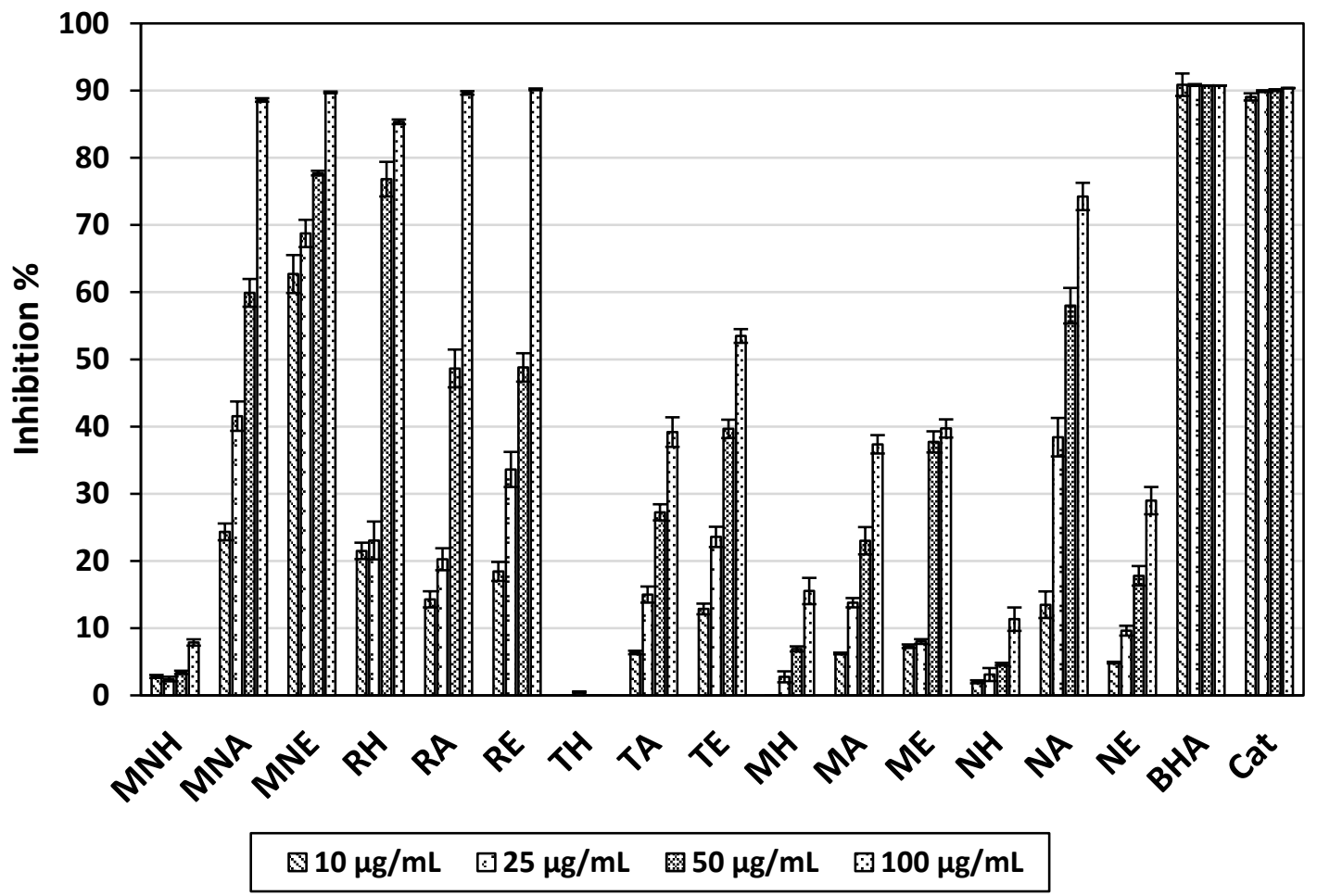

${ }^{\text {a }}$ Mean of triplicate measurements \pm standard deviation

Figure 2. ABTS cation radical scavenging activity of the plant extracts, BHA and $\mathrm{Cat}^{\mathrm{a}}$ 
Table 3. Anticholinesterase activity of the plant extracts ${ }^{\mathrm{a}}$

\begin{tabular}{lll}
\hline Samples & AChE Inhibition (\%) & BChE Inhibition (\%) \\
\hline MNH & NA $^{\mathrm{b}}$ & $83.29 \pm 2.33$ \\
MNA & $1.30 \pm 0.26$ & $66.22 \pm 0.38$ \\
MNE & NA & $69.70 \pm 2.95$ \\
RH & $17.73 \pm 1.93$ & $72.64 \pm 1.59$ \\
RA & $5.01 \pm 0.07$ & $77.41 \pm 2.31$ \\
RE & $4.19 \pm 0.61$ & $72.64 \pm 1.59$ \\
TH & $26.88 \pm 1.85$ & $79.96 \pm 2.20$ \\
TA & NA & $71.00 \pm 1.64$ \\
TE & NA & $64.60 \pm 2.68$ \\
MH & $30.59 \pm 1.96$ & $84.15 \pm 2.27$ \\
MA & $47.83 \pm 1.23$ & $88.73 \pm 0.88$ \\
ME & $20.71 \pm 2.49$ & $81.89 \pm 2.25$ \\
NH & $11.61 \pm 1.13$ & $65.08 \pm 2.21$ \\
NA & $38.63 \pm 2.21$ & $84.78 \pm 3.06$ \\
NE & $44.75 \pm 1.36$ & $92.68 \pm 3.89$ \\
Galanthamine & $82.51 \pm 0.25$ & $88.44 \pm 0.50$
\end{tabular}

${ }^{\text {a }}$ Mean of triplicate measurements \pm standard deviation

${ }^{\mathrm{b}}$ Not active

${ }^{\mathrm{c}}$ Standart drug

\section{Conclusion}

Antioxidants and their protective effects against many diseases have been examined in several studies. In the present work, five plants, which have been used as traditional medicines for digestion system problems and nutraceuticals, were investigated in terms of total phenolic and total flavonoid contents, antioxidant capacities and anticholinesterase potentials. Their antioxidant activities could be related with their positive effects in the treatment of digestion system diseases, which may be enlightened by further pharmacological studies. Also phytochemical studies may be performed to isolate active compounds from the extracts exhibiting high antioxidant and anticholinesterase potentials.

\section{Compliance with Ethical Standard}

Conflict of interests: The authors declare that for this article they have no actual, potential or perceived conflict of interests.

Financial disclosure: This work was supported by Scientific Research Project Coordination Unit of Istanbul University (Project number: 50585).

\section{References}

Baytop, T. (1984). Türkiye'de Bitkilerle Tedavi (Geçmişte ve Bugün). İstanbul: İstanbul University Press, p. 184, 221-2, 226, 258-9, 417, ISBN 9789754200218
Benso, B., Franchin, M., Massarioli, A.P., Paschoal, J.A.R., Alencar, S.M., Franco, G.C.N., Rosalen, P.L. (2016). Anti-inflammatory, anti-osteoclastogenic and antioxidant effects of Malva sylvestris extract and fractions: in vitro and in vivo studies. PLoS One 11(9), e0162728.

Blois, M.S. (1958). Antioxidant determinations by the use of a stable free radical. Nature, 181, 1199-1200.

Boğa, M., Hacıbekiroğlu, I., Kolak, U. (2011). Antioxidant and anticholinesterase activities of eleven edible plants. Pharmaceutical Biology, 49, 290-295.

Boğa, M., Ertaş, A., Yılmaz, M.B., Kızıl, M., Çeken, B., Haşimi, N., Yılmaz Özden, T., Demirci, S., Yener, İ., Deveci, Ö. (2016). UHPLC-ESI-MS/MS and GC-MS analyses on phenolic, fatty acid and essential oil of $\mathrm{Ver}$ bascum pinetorum with antioxidant, anticholinesterase, antimicrobial and DNA damage protection effects. Iranian Journal of Pharmaceutical Research, 15, 393405.

Craft, B.D., Kerrihard, A.L., Amarowicz, R., Pegg, R.B. (2012). Phenol-based antioxidants and the in vitro methods used for their assessment. Comprehensive Reviews in Food Science and Food Safety, 11, 148-173. 
Dudonné, S., Vitrac, X., Coutière, P., Woilllez, M., Mérillon, J-M. (2009). Comparative study of antioxidant properties and total phenolic content of 30 plant extracts of industrial interest using DPPH, ABTS, FRAP, SOD, and ORAC assays. Food Chemistry, 57, 17681774.

Ellman, G.L., Courtney, K.D., Andres, V., Featherston, R.M. (1961). A new and rapid colorimetric determination of acetylcholinesterase activity. Biochemical Pharmacology, 7, 88-95.

Ertaş, A., Boğa, M., Haşimi, N., Yeşil, Y., Gören, A.C., Topçu, G., Kolak, U. (2014). Antioxidant, anticholinesterase, and antimicrobial activities and fatty acid constituents of Achillea cappadocica Hausskn. et Bornm. Turkish Journal of Chemistry, 38, 592-599.

Ferreira, A., Proenca, C., Serralheiro, M.L.M., Araujo, M.E.M. (2006). The in vitro screening for acetylcholinesterase inhibition and antioxidant activity of medicinal plants from Portugal. Journal of Ethnopharmacology, $108,7-31$.

Gholamhoseinian, A., Moradi, M.N., Sharifi-Far, F. (2009). Screening the methanol extracts of some Iranian plants for acetylcholinesterase inhibitory activity. Research in Pharmaceutical Sciences, 4, 105-112.

Gülçin, İ., Küfrevioğlu, Ö.İ., Oktay, M., Büyükokuroğlu, M.E. (2004). Antioxidant, antimicrobial, antiulcer and analgesic activities of nettle (Urtica dioica L.). Journal of Ethnopharmacology, 90, 205-215.

Hamad, İ., Erol-Dayi, Ö., Pekmez, M., Önay-Uçar, E., Arda, N. (2010). Antioxidant and cytotoxic activities of Aphanes arvensis extracts. Plant Foods for Human $\mathrm{Nu}$ trition, 65, 45-49.

Hartman, R.E. (2009). Phytochemicals in cell function and Alzheimer's disease pathology. In L. Packer, H. Sies, M. Eggersdorfer \& E. Cadenas (Eds.) Micronutrients and Brain Health (p. 225-241). New York, NY: CRC press. ISBN 9781420073515

Howes, M-J.R., Perry, N.S.L., Houghton, P.F. (2003). Plants with traditional uses and activities, relevant to the management of Alzheimer's disease and other cognitive disorders. Phytotherapy Research, 17, 1-18.
Keskin, C., Aktepe, N., Yükselten, Y., Sunguroğlu, A., Boğa, M. (2017). In-vitro antioxidant, cytotoxic, cholinesterase inhibitory activities and anti-genotoxic effects of Hypericum retusum Aucher flowers, fruits and seeds methanol extracts in human mononuclear leukocytes. Iranian Journal of Pharmaceutical Research, $16,210-220$.

Liang, N., Kitts, D.D. (2014). Antioxidant property of coffee components: Assessment of methods that define mechanisms of action. Molecules, 19, 19180-19208.

Nasri, H., Baradaran, A., Shirzad, H., Rafieian-Kopaei, M. (2014). New concepts in nutraceuticals as alternative for pharmaceuticals. International Journal of Preventive Medicine, 5, 1487-1499.

Nishikimi, M., Rao, N.A., Yagi, K. (1972). The occurrence of superoxide anion in the reaction of reduced phenazine methosulfate and moleculer oxygen. Biochemical and Biophysical Research Communications, 46, 849854.

Oh, J., Jo, H., Cho, A.R., Kim, S-J., Han, J. (2012). Antioxidant and antimicrobial activities of various leafy herbal teas. Food Control, 31, 403-409.

Orhan, İ., Aslan, S., Kartal, M., Şener, B., Başer, K.H.C. (2008). Inhibitory effect of Turkish Rosmarinus officinalis $\mathrm{L}$. on acetylcholinesterase and butyrylcholinesterase enzymes. Food Chemistry, 108, 663-668.

Park, Y.K., Koo, M.H., Ikegaki, M., Contado, J.L. (1997). Comparison of the flavonoid aglycone contents of Apis mellifera propolis from various regions of Brazil. $\mathrm{Bra}$ zilian Archives of Biology and Technology, 40, 97-106.

Piazzi, L., Cavalli, A., Colizzi, F., Belluti, F., Bartolini, M., Mancini, F., Recanatini, M., Andrisano, V., Rampa, A. (2008). Multi-target-directed coumarin derivatives: hAChE and BACE1 inhibitors as potential anti-Alzheimer compounds. Bioorganic \& Medicinal Chemistry Letters, 18, 423-426.

Re, R., Pellegrini, N., Proteggente, A., Pannala, A., Yang, M., Rice-Evans, C. (1999). Antioxidant activity applying an improved ABTS radical cation decolorization assay. Free Radical Biology \& Medicine, 26, 12311237. 
Reische, D.W., Lillard, D.A., Eitenmiller, R.R. (2002). Antioxidants. In C.C. Akoh \& D.B. Min (Eds.), Food Lipids: Chemistry, Nutrition, and Biotechnology (p. 489516). New York, NY: Marcel Dekker Inc. ISBN 0-8247-0749-4

Samuelsson, G., Bohlin L. (1999). Drugs of natural origin: a text book of pharmacognosy. Stockholm: Swedish P'ceutical Press, ISBN 9789186274818
Slinkard, K., Singleton, V.L. (1977). Total phenol analysis automation and comparison with manual methods. American Journal of Enology and Viticulture, 28, 4955.

Wong, S.P., Leong, L.P., Koh, J.H.W. (2006). Antioxidant activities of aqueous extracts of selected plants. Food Chemistry, 99, 775-783. 